Proc. Indian Acad. Sci. (Chem. Sci.), Vol. 105, No. 6, December 1993, pp. 567-574.

(C) Printed in India.

\title{
Amine-assisted photochemical dehalogenation of haloanthracenes (9-halo and 9,10-dihalo compounds) and their triplet formation
}

\author{
TOSHIHIRO NAKAYAMA, KAZUYASU IBUKI and KUMAO \\ HAMANOUE* \\ Department of Chemistry, Kyoto Institute of Technology, Matsugasaki, Sakyo-ku, Kyoto 606, \\ Japan
}

\begin{abstract}
Steady-state photolysis of haloanthracenes (XA; 9,10-dichloro, 9,10-dibromo, 9-chloro and 9-bromo compounds) in acetonitrile-amine (triethylamine or N,N-dimethylaniline) causes the consecutive reactions; 9,10-dihalo compounds $\rightarrow$ 9-halo compounds $\rightarrow$ anthracene. Although both the lowest excited singlet $\left[{ }^{1} \mathrm{XA}\left(\mathrm{S}_{1}\right)\right]$ and triplet $\left[{ }^{3} \mathrm{XA}\left(\mathrm{T}_{1}\right)\right]$ states of XA are quenched by amine, the appearance of absorption spectra due to the haloanthracene radical anions $\left(\mathrm{XA}^{-}{ }^{-}\right.$) within the duration of nanosecond pulse excitation indicates that the intermediates for dehalogenation of $\mathrm{XA}$ are $\mathrm{XA}^{-}{ }^{-}$produced by a diffusion-controlled reaction of ${ }^{1} \mathrm{XA}\left(\mathrm{S}_{1}\right)$ with the ground-state amine yielding the singlet exciplexes [ $\left.{ }^{1}(\mathrm{XA} \text {-amine })^{*}\right]$ which decompose rapidly into $\mathrm{XA}^{-}$and the amine radical cations. Moreover, an amine-assisted formation of ${ }^{3} \mathrm{XA}\left(\mathrm{T}_{1}\right)$ has been attributed to the intersystem crossing from ${ }^{1}$ (XA-amine $)^{*}$ to the triplet exciplexes $\left[{ }^{3}(\mathrm{XA} \text {-amine })^{*}\right]$ followed by decomposition into ${ }^{3} \mathrm{XA}\left(\mathrm{T}_{1}\right)$ and ground-state amine.
\end{abstract}

Keywords. Photochemical dehalogenation of haloanthracenes by amines; amine-assisted triplet formation of haloanthracenes; haloanthracene radical anions; 9, 10-dihalo and 9-halo anthracenes.

\section{Introduction}

The photoinduced dehalogenation of aromatic halocompounds by amine is well known and the generally suggested mechanism is that the radical anions produced via the exciplexes of singlet halocompounds with ground-state amines are the reaction intermediates which decompose into the aryl radicals and the halogen anions (Ohashi et al 1973; Tsujimoto et al 1975; Bunce et al 1976, 1978; Chittin et al 1978; Davidson and Goodwin 1981; Fulara and Latowski 1990; Saeva 1990). Upon investigation of the photochemical debromination of meso-substituted bromoanthracenes $(9,10$ - dibromo and 9-bromo compounds) by amine [triethylamine (TEA) or $\mathrm{N}, \mathrm{N}$-dimethylaniline (DMA)] in acetonitrile, we have also concluded that the reaction intermediates are the bromoanthracene radical anions produced by a diffusion-controlled reaction of the lowest excited singlet states of bromoanthracenes with the ground-state amines yielding singlet exciplexes followed by decomposition into bromoanthracene radical anions and amine radical cations (Hamanoue et al 1984b). Meanwhile, Soloveichik et al (1989) have found that the photochemical dechlorination of 9,10-dichloroanthracene by DMA in acetonitrile is strongly retarded upon addition of azulene (or

* For correspondence 


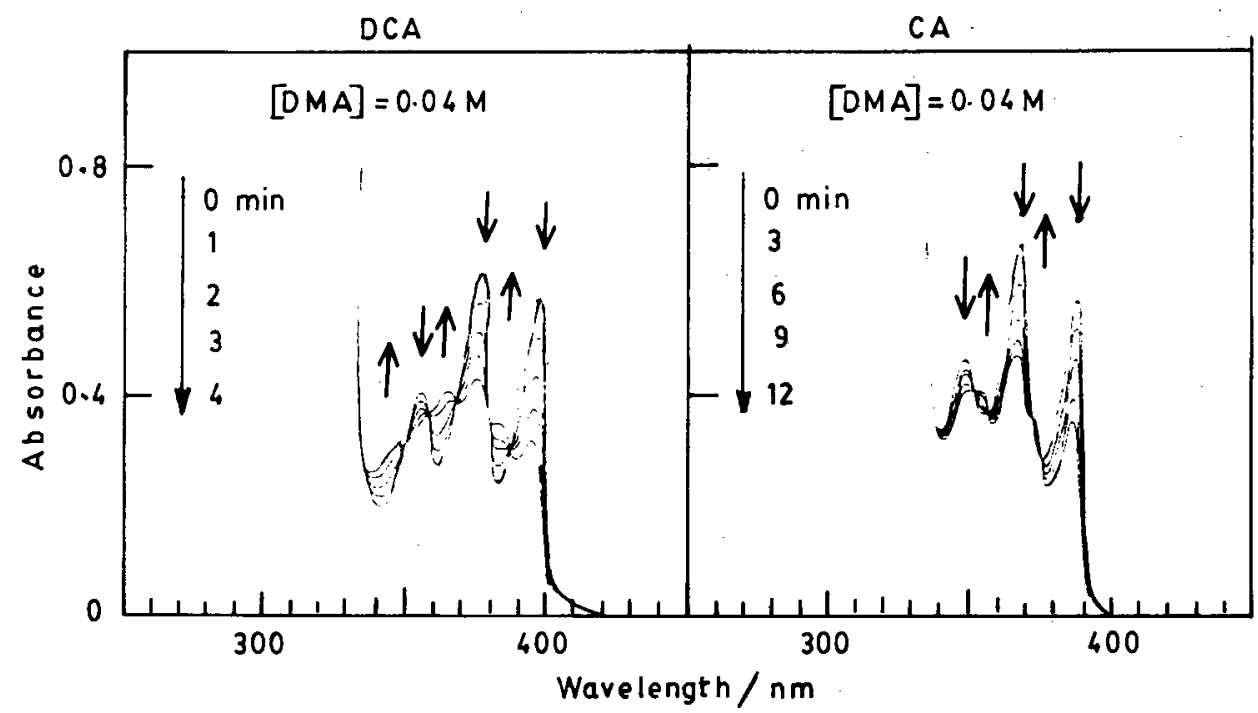

Figure 1. Dechlorination of DCA and CA upon steady-state photolysis in $\mathrm{CH}_{3} \mathrm{CN} / \mathrm{DMA}$ $(0.04 \mathrm{M})$ at room temperature.

ferrocene) and that the increment of triplet decay rate constant with increasing DMA concentration is not linear. Based on these results, they have concluded that the haloanthracene radical anions produced via the exciplexes of singlet haloanthracenes with ground-state amine do not participate in the dehalogenation but the exciplexes of triplet haloanthracenes with ground-state amine are the reaction intermediates. In order to contest this conclusion, the present review deals with our recent results obtained by steady-state photolysis and nanosecond laser photolysis of haloanthracenes (9,10-dichloro, 9,10-dibromo, 9-chloro and 9-bromo compounds) by amine (TEA or DMA) in acetonitrile at room temperature (Nagamura et al 1991, 1992; Hamanoue et al 1992, 1993).

\section{Photochemical reaction of haloanthracenes and their triplet formation in acetonitrile/ amine}

Figure 1 shows the absorption spectral change caused upon steady-state photolysis of 9,10-dichloro (DCA) and 9-chloro (CA) compounds in acetonitrile $\left(\mathrm{CH}_{3} \mathrm{CN}\right)$ containing 0.04 M DMA at room temperature. Since similar results are also obtained not only in $\mathrm{CH}_{3} \mathrm{CN} / \mathrm{TEA}(0.04 \mathrm{M})$ but also for 9,10-dibromo (DBA) and 9-bromo (BA) compounds in $\mathrm{CH}_{3} \mathrm{CN} /$ amine $(0.04 \mathrm{M}$ DMA or TEA), and since the photoproducts from 9,10-dihalo compounds and 9-halo compounds have been identified to be 9-halo compounds and anthracene, respectively, it can safely be concluded that the dehalogenation of 9,10-dihalo compounds by amine proceeds by the consecutive reactions; 9,10-dihalo compounds $\rightarrow$ 9-halo compounds $\rightarrow$ anthracene. Although Soloveichik et al (1989) have reported that the quantum yield for dechlorination of DCA by DMA decreases remarkably upon addition of azulene or ferrocene, we have confirmed that addition of these additives $\left(1 \times 10^{-4} \mathrm{M}\right)$ does not affect the decrement 


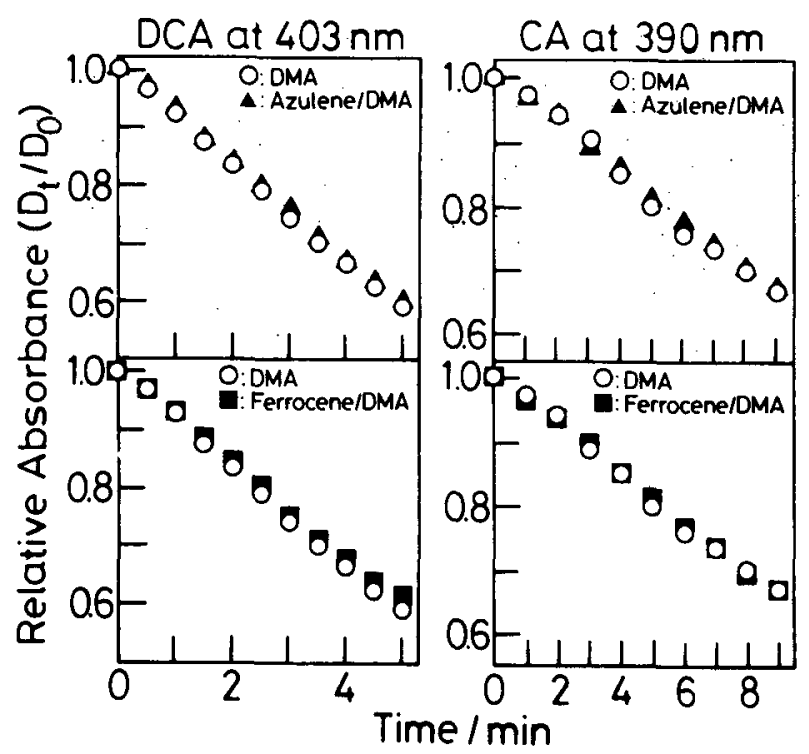

Figure 2. Decrement in the relative absorbances $\left(D_{t} / D_{0}\right)$ of DCA and CA during steadystate photolysis at room temperature in $\mathrm{CH}_{3} \mathrm{CN} / \mathrm{DMA}(0.04 \mathrm{M})$ without $(\mathrm{O})$ and with $1 \times 10^{-4} \mathrm{M}$ azulene $(\mathbf{A})$ [or ferrocene $(\boldsymbol{D})$ ].

in the relative reactant absorbances $\left(D_{t} / D_{0}\right)$ during steady-state photolysis of haloanthracenes (XA) in $\mathrm{CH}_{3} \mathrm{CN} /$ amine $(0.04 \mathrm{M})$; typical examples obtained for chloro compounds in $\mathrm{CH}_{3} \mathrm{CN} / \mathrm{DMA}(0.04 \mathrm{M})$ are shown in figure 2 , where $D_{t}$ and $D_{0}$ are the absorbances measured at photolysis time of $t$ and $0 \mathrm{~min}$, respectively.

We have found that the intensity of triplet-triplet $\left(T^{\prime} \leftarrow T_{1}\right)$ absorption spectra due to the lowest excited triplet states $\left[{ }^{3} \mathrm{XA}\left(T_{1}\right)\right]$ of XA decreases with increasing amine concentration, but a normalization of the $T^{\prime} \leftarrow T_{1}$ absorption spectrum in the presence of amine to those in the absence of amine reveals no change in the spectral profile. Since all the $T^{\prime} \leftarrow T_{1}$ absorption spectra are recorded at a decay time of $70 \mathrm{~ns}$ and a gate time of $20 \mathrm{~ns}$ and since the $T^{\prime} \leftarrow T_{1}$ absorptions are found to decay in the microsecond time regime even in the presence of amine, the intensity decrease of $T^{\prime} \leftarrow T_{1}$ absorption spectra caused upon addition of amine can be ascribed to the decrement in the yields of the lowest excited singlet states $\left[{ }^{1} \mathrm{XA}\left(\mathrm{S}_{1}\right)\right]$ of XA. Calculating the intensities of $T^{\prime} \leftarrow T_{1}$ absorption spectra in the absence $\left(I_{0}^{T}\right)$ and presence $\left(I_{A}^{T}\right)$ of amine, the ratios of $I_{0}^{T} / I_{A}^{T}$ are plotted against amine concentration as shown by open circles in figures 3 and 4 . If ${ }^{3} \mathrm{XA}\left(T_{1}\right)$ are produced only via the indirect ${ }^{1} \mathrm{XA}\left(S_{1}\right) \rightarrow$ ${ }^{3} \mathrm{XA}\left(T_{n}\right) \rightarrow{ }^{3} \mathrm{XA}\left(T_{1}\right)$ intersystem crossing through an adjacent higher excited triplet ( $T_{n}$ ) state (Hamanoue et al 1983; Tanaka et al 1983), the ratio of $I_{0}^{T} / I_{A}^{T}$ can be given by

$$
I_{0}^{T} / I_{A}^{T}=1+k_{q} \tau[\text { amine }],
$$

where $\tau$ is the fluorescence lifetime of ${ }^{1} \mathrm{XA}\left(S_{1}\right)$ in the absence of amine and $k_{q}$ is the fluorescence quenching rate constant by amine. Hence, the value of $k_{q}$ obtained from $I_{0}^{T} / I_{A}^{T}$ should be equal to that obtained by the Stern-Volmer plot of $I_{0}^{F} / I_{A}^{F}$ against amine concentration; $I_{0}^{F}$ and $I_{A}^{F}$ are the fluorescence intensities in the absence and presence of amine, respectively. In contrast, as shown in figures 3 and 4 , the values 


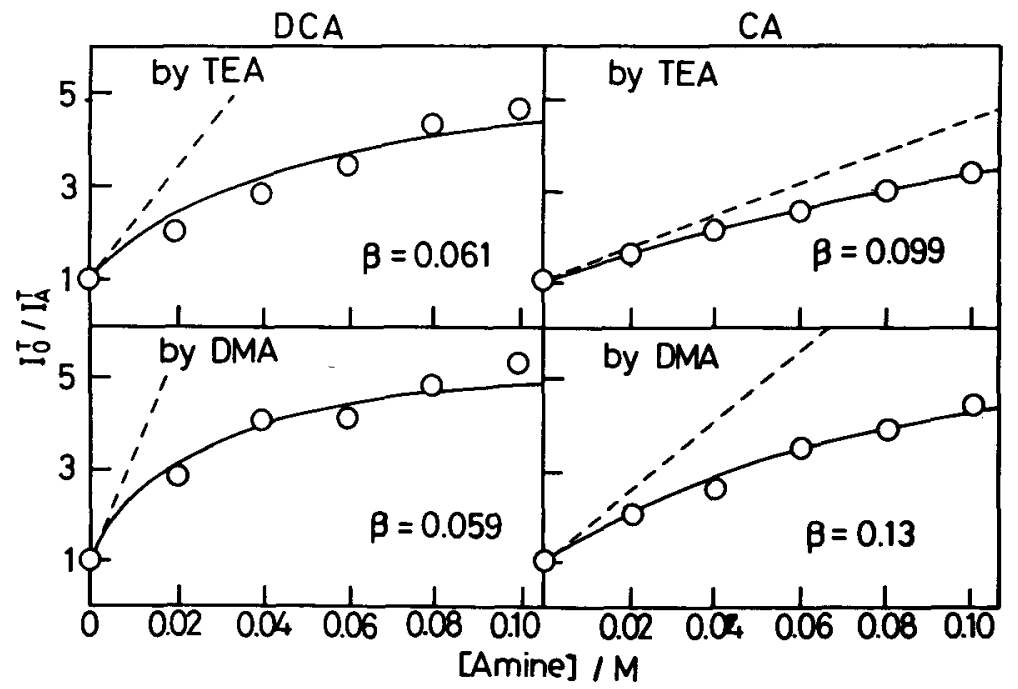

Figure 3. Plots of $I_{0}^{T} / I_{A}^{T}$ against amine concentration obtained for DCA and $\mathrm{CA}$ in $\mathrm{CH}_{3} \mathrm{CN}$ at room temperature. The dashed lines correspond to the Stern-Volmer plots of fluorescence intensities against amine concentration, and the full lines are simulated by (1) using the values of $k_{q}$ obtained from the fluorescence quenching by amine: $k_{q}=1.4 \times 10^{10}$ (by TEA) and $2.7 \times 10^{10}$ (by DMA) $\mathrm{M}^{-1} \mathrm{~s}^{-1}$ for DCA, and $k_{q}=1.1 \times 10^{10}$ (by TEA) and $2.4 \times 10^{10}$ (by DMA) $\mathrm{M}^{-1} \mathrm{~s}^{-1}$ for CA.

of $I_{0}^{T} / I_{A}^{T}$ (open circles) deviate from the dashed lines obtained from $I_{0}^{F} / I_{A}^{F}$ giving $k_{q}$ of the order for that of a diffusion-controlled reaction. The smaller values of $I_{0}^{T} / I_{A}^{T}$ than those of $I_{0}^{F} / I_{A}^{F}$ may reflect an additional formation of ${ }^{3} \mathrm{XA}\left(T_{1}\right)$ by amine.

Probably, the additional formation of ${ }^{3} \mathrm{XA}\left(T_{1}\right)$ in the presence of amine may be interpreted in terms of the intersystem crossing from ${ }^{1}$ (XA-amine)* to the triplet exciplexes $\left[{ }^{3}(\mathrm{XA} \text {-amine })^{*}\right]$ followed by decomposition into ${ }^{3} \mathrm{XA}\left(T_{1}\right)$ and groundstate amine as shown by scheme 1 .
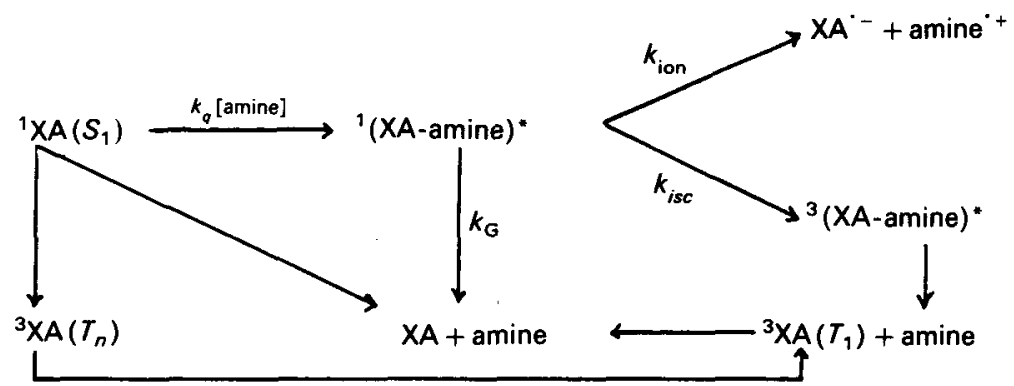

Scheme 1.

Hence, $I_{0}^{T} / I_{A}^{T}$ should be given by;

$$
\begin{aligned}
\frac{I_{0}^{T}}{I_{A}^{T}} & =\frac{1+k_{q} \tau[\text { amine }]}{1+\alpha[\text { amine }]}, \\
\alpha & =\beta k_{q} / k_{i s c}, \\
\beta & =k_{i s c}^{\prime} /\left(k_{\mathrm{G}}+k_{\text {ion }}+k_{i s c}^{\prime}\right) .
\end{aligned}
$$




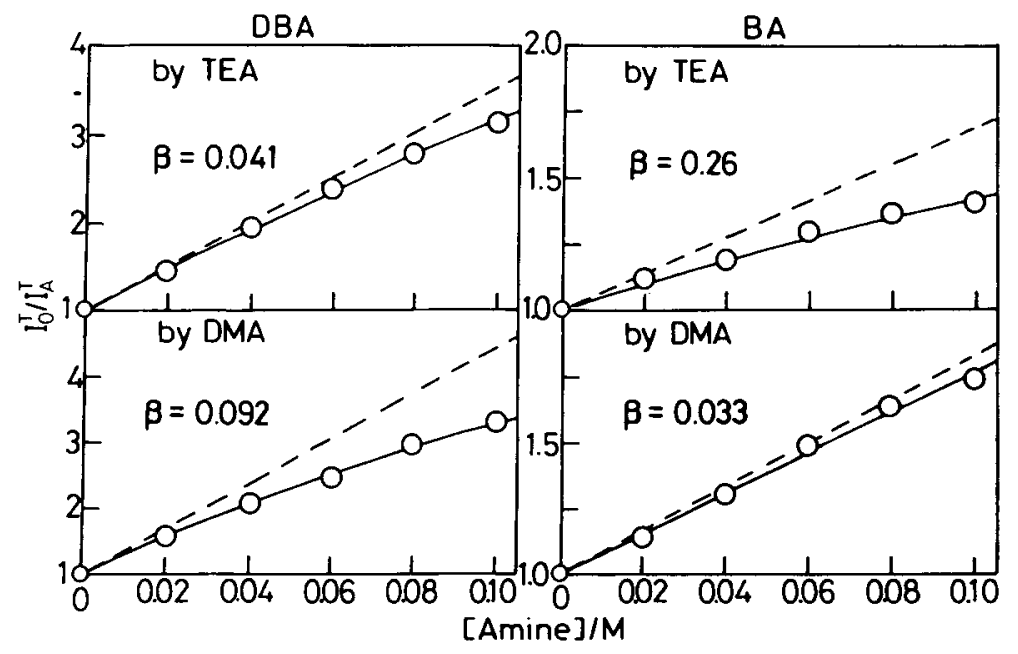

Figure 4. Plots of $I_{0}^{T} / I_{A}^{T}$ against amine concentration obtained for DBA and BA in $\mathrm{CH}_{3} \mathrm{CN}$ at room temperature. The dashed lines correspond to the Stern-Volmer plots of fluorescence intensities against amine concentration, and the full lines are simulated by (1) using the values of $k_{q}$ obtained from the fluorescence quenching by amine: $k_{q}=2.0 \times 10^{10}$ (by TEA) and $2.7 \times 10^{10}$ (by DMA) $\mathrm{M}^{-1} \mathrm{~s}^{-1}$ for DBA, and $k_{q}=4.3 \times 10^{10}$ (by TEA) and $5.2 \times 10^{10}$ (by DMA) $\mathrm{M}^{-1} \mathrm{~s}^{-1}$ for BA.

By a best-fit of the calculated values $\left\{\left(1+k_{q} \tau\right.\right.$ [amine $\left.]\right) /(1+\alpha$ [amine $\left.\left.]\right)\right\}$ to the experimental values, the change of $I_{0}^{T} / I_{A}^{T}$ with amine concentration can well be reproduced as shown by the full curves in figures 3 and 4 . Since the fluorescence quantum yield $\left(\Phi_{F}\right)$ in $\mathrm{CH}_{3} \mathrm{CN}$ without amine are found to be 0.64 (DCA), 0.02 (CA), 0.09 (DBA) and $0.04(\mathrm{BA})$, the rate constants $\left(k_{i s c}\right)$ for the ${ }^{1} \mathrm{XA}\left(S_{1}\right) \rightarrow{ }^{3} \mathrm{XA}\left(T_{n}\right)$ intersystem crossing are calculated to be $4.2 \times 10^{7}$ (DCA), $3.0 \times 10^{8}(\mathrm{CA}), 7 \cdot 1 \times 10^{8}(\mathrm{DBA})$ and $6.0 \times 10^{9}$ (BA) $\mathrm{s}^{-1}$. Using the best-fit values of $\alpha$, the values of $\beta$ are calculated as indicated in figures 3 and 4 , and the greater values of $k_{q}$ [amine] in $\mathrm{CH}_{3} \mathrm{CN} /$ amine $(1 \mathrm{M})$, i.e., $1.4-2.7 \times 10^{10}$ (DCA), $1.1-2.4 \times 10^{10}$ (CA), $2.0-2.7 \times 10^{10}$ (DBA) and $4.3-5.2 \times$ $10^{10}(\mathrm{BA}) \mathrm{s}^{-1}$, compared with those of $k_{i s c}$ indicate that ${ }^{1}\left(\mathrm{XA}\right.$-amine) ${ }^{*}$ are produced with efficiencies of $\sim 1.0$ (DCA, CA), 0.97 (DBA) and $0.88-0.90$ (BA), and that almost all ${ }^{3} \mathrm{XA}\left(T_{1}\right)$ are produced via the indirect ${ }^{1}(\mathrm{XA} \text {-amine })^{*} \rightarrow{ }^{3}(\mathrm{XA} \text {-amine })^{*} \rightarrow{ }^{3} \mathrm{XA}\left(T_{1}\right)$ process shown in scheme 1 .

\section{Formation of the haloanthracene radical anions via the singlet exciplexes of ${ }^{1} \mathrm{XA}\left(S_{1}\right)$ with ground-state amine}

Figure 5 shows the transient absorption spectra obtained by nanosecond laser photolysis of DCA and $\mathrm{CA}$ in $\mathrm{CH}_{3} \mathrm{CN} /$ amine $(1 \mathrm{M})$ at room temperature; the spectra are recorded at a delay time of $0 \mathrm{~ns}$ and a gate time of $50 \mathrm{~ns}$. Similar transients are also obtained for DBA and BA. In the absence of amine, however, only the $T^{\prime} \leftarrow T_{1}$ absorptions (bands $\mathrm{C}$ and $\mathrm{D}$ ) of ${ }^{3} \mathrm{XA}\left(T_{1}\right)$ can be seen. We have assigned bands $F$, $G$ and $H$ to absorptions of the haloanthracene radical anions $\left(\mathrm{XA}^{-}\right)$based on the following facts: (1) The spectra with bands $F-H$ are identical with those of $\mathrm{XA}^{-}$ which are produced by pulse radiolysis of XA at room temperature in $\mathrm{CH}_{3} \mathrm{CN}$ 


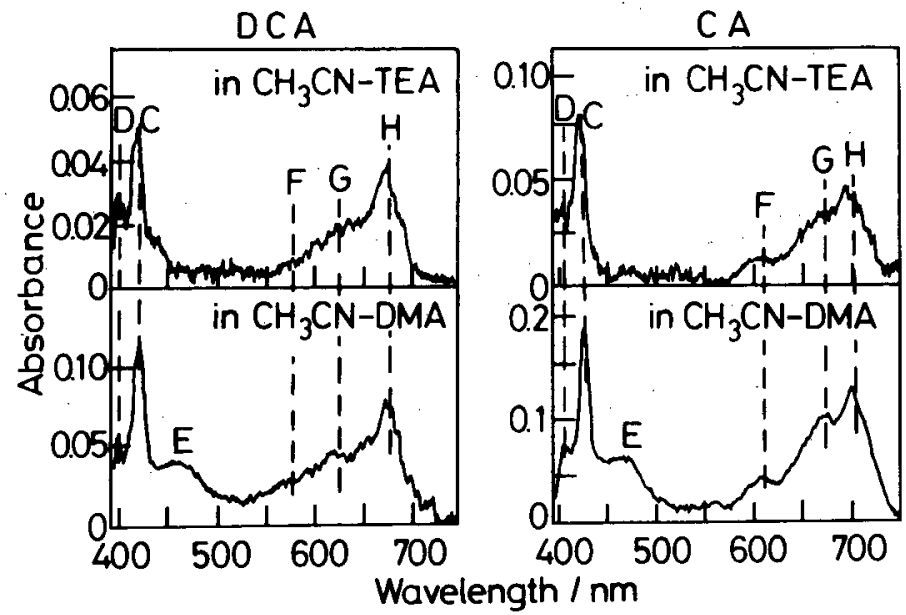

Figure 5. Transient absorption spectra obtained by nanosecond laser photolysis of DCA and $\mathrm{CA}$ in $\mathrm{CH}_{3} \mathrm{CN} /$ amine $(1 \mathrm{M})$ at room temperature.

without amine (Hamanoue et al 1984a) or $\gamma$-radiolysis of XA at $77 \mathrm{~K}$ in 2-methyltetrahydrofuran without amine. (2) Band $E$ observed in the presence of DMA is very similar to that of the published absorption spectrum due to $\mathrm{DMA}^{+}$(Hamil 1968; Shida 1988; Iwamura and Eaton 1991); no clear observation of the absorption band due to $\mathrm{TEA}^{++}$may be ascribed to its weak absorption (Shida 1988).

We propose that $\mathrm{XA}^{-}$- are produced by a diffusion-controlled reaction of ${ }^{1} \mathrm{XA}\left(S_{1}\right)$ with ground-state amine yielding ${ }^{1}$ (XA-amine)* followed by decomposition into $\mathrm{XA}^{*}$ and the amine radical cations (amine ${ }^{+}$): Because, (1) ${ }^{3} \mathrm{XA}\left(T_{1}\right)$ in $\mathrm{CH}_{3} \mathrm{CN}$ decay following a single-exponential function irrespective of absence and presence of amine, and the decay rate constants thus obtained increase linearly with increasing amine concentration; (2) the quenching rate constants $\left(k_{q}^{\prime} \approx 10^{4}-10^{5} \mathrm{M}^{-1} \mathrm{~s}^{-1}\right)$ of ${ }^{3} \mathrm{XA}\left(T_{1}\right)$ by amine, however, are much smaller than those $\left(k_{q} \approx 10^{10} \mathrm{M}^{-1} \mathrm{~s}^{-1}\right)$ obtained for the quenching of ${ }^{1} \mathrm{XA}\left(S_{1}\right)$ by amine, indicating that the spectra observed at 0 -ns delay (shown in figure 5) cannot be attributed to $\mathrm{XA}^{-}$- produced by a reaction of ${ }^{3} \mathrm{XA}\left(T_{1}\right)$ with amine.

The absorptions of $\mathrm{XA}^{-}$in $\mathrm{CH}_{3} \mathrm{CN} /$ amine $(1 \mathrm{M})$ decay with time following a singleexponential function and the decay rate constants $\left(k_{\mathrm{XA}^{-}-}\right)$obtained are of the order of $10^{4}-10^{5} \mathrm{~s}^{-1}$; typical decay curves obtained for DCA and CA in $\mathrm{CH}_{3} \mathrm{CN} / \mathrm{DMA}$ $(1 \mathrm{M})$ are shown in figure 6 . If ${ }^{3}\left(\mathrm{XA}\right.$-amine) ${ }^{*}$ produced by a reaction of ${ }^{3} \mathrm{XA}\left(T_{1}\right)$ with ground-state amine as proposed by Soloveichik et al (1989) give rise to the formation of $\mathrm{XA}^{-}$, the values of $k_{\mathrm{XA}^{*}-}$ shown in figure 6 indicate that one cannot confirm the formation of $\mathrm{XA}^{-}{ }^{-}$in $\mathrm{CH}_{3} \mathrm{CN} / \mathrm{DMA}(1 \mathrm{M})$ owing to the larger values of $k_{\mathrm{XA}^{*}-}=3.5 \times 10^{5}(\mathrm{DCA})-9.5 \times 10^{5}(\mathrm{CA}) \mathrm{s}^{-1}$ compared with those of $k_{q}^{\prime}$ [DMA] $=$ $5.0 \times 10^{4}(\mathrm{DCA})-2.2 \times 10^{5}(\mathrm{CA}) \mathrm{s}^{-1}$. In $\mathrm{CH}_{3} \mathrm{CN} / \mathrm{TEA}(1 \mathrm{M})$, however, the rise and decay of absorptions due to $\mathrm{XA}^{-}$- should be detectable in the microsecond time regime, because $k_{\mathrm{XA}^{-}}=2.8 \times 10^{4}(\mathrm{DCA})-9.7 \times 10^{4}(\mathrm{CA}) \mathrm{s}^{-1}$ are smaller than $k_{q}^{\prime}[\mathrm{TEA}]=$ $1.8 \times 10^{5}(\mathrm{DCA})-2.3 \times 10^{5}(\mathrm{CA}) \mathrm{s}^{-1}$. In contrast, no such evidence has been obtained. Even if the dehalogenation does occur in ${ }^{3}$ (XA-amine)* produced by a reaction of ${ }^{3} \mathrm{XA}\left(T_{1}\right)$ with ground-state amine and no $\mathrm{XA}^{-}$are produced, the following results cannot support the triplet exciplex mechanism: (1) The decay rate constants of 


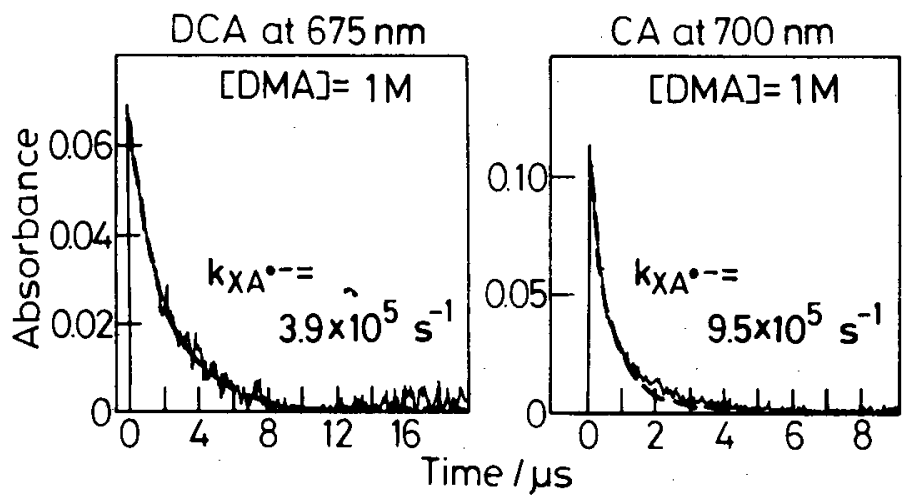

Figure 6. Decays of absorptions (full lines) due to $\mathrm{DCA}^{-}$- and $\mathrm{CA}^{-}-$in $\mathrm{CH}_{3} \mathrm{CN} / \mathrm{DMA}$ (1 M) at room temperature. The dashed lines are simulated single-exponential functions with decay rate constants $\left(k_{\mathbf{x A}^{-}-}\right)$indicated in the figure.

${ }^{3} \mathrm{XA}\left(T_{1}\right)$ in $\mathrm{CH}_{3} \mathrm{CN} /$ amine increase linearly with increasing amine concentration, showing no existence of such an equilibrium between ${ }^{3} \mathrm{XA}\left(T_{1}\right)+$ amine and ${ }^{3}$ (XA-amine)* as proposed by Soloveichik et al (1989); during decrement of the $T^{\prime} \leftarrow T_{1}$ absorption spectra of ${ }^{3} \mathrm{XA}\left(T_{1}\right)$ with time in $\mathrm{CH}_{3} \mathrm{CN} /$ amine $(0.04 \mathrm{M})$, moreover, no change in the spectral profile can be seen. (2) Addition of azulene or ferrocene in $\mathrm{CH}_{3} \mathrm{CN}$ accelerates the decay of ${ }^{3} \mathrm{XA}\left(T_{1}\right)$ with quenching rate constants of the order of $10^{8}-10^{9} \mathrm{M}^{-1} \mathrm{~s}^{-1}$, while figure 2 reveals no effects of these additives on the decrement of reactant absorptions during steady-state photolysis in $\mathrm{CH}_{3} \mathrm{CN} / \mathrm{DMA}$ $(0.04 \mathrm{M})$; similar results are also obtained in $\mathrm{CH}_{3} \mathrm{CN} / \mathrm{TEA}(0.04 \mathrm{M})$. (3) The quantum yields $\left(\Phi_{R}\right)$ for the dechlorination of DCA yielding $\mathrm{CA}$ in $\mathrm{CH}_{3} \mathrm{CN} /$ amine $(0.08 \mathrm{M})$ are found to be greater than those in $\mathrm{CH}_{3} \mathrm{CN} /$ amine $(0.04 \mathrm{M})$, while the quantum yields $\left(\Phi_{T}\right)$ for the formation of ${ }^{3} \mathrm{XA}\left(T_{1}\right)$ decrease with increasing amine concentration; in the presence of $0.08 \mathrm{M}$ DMA, moreover, $\Phi_{R}=0.117$ is greater than $\Phi_{T}=0.073$.

\section{Conclusion}

All the results obtained so far are consistent with those reported in our previous paper (Hamanoue et al 1984b). Thus, again we conclude that the intermediates for the photochemical dehalogenation of haloanthracenes (XA) are really their radical anions $\left(\mathrm{XA}^{-}\right)$produced by a diffusion-controlled reaction of ${ }^{1} \mathrm{XA}\left(\mathrm{S}_{1}\right)$ with groundstate amine yielding the singlet exciplexes $\left[{ }^{1}(\mathrm{XA} \text {-amine })^{*}\right]$ followed by decomposition into $\mathrm{XA}^{-}$and amine ${ }^{+}$(cf. scheme 1).

The absorption spectra with bands $D-F$ shown in figure 5 might be ascribed to the absorptions of ${ }^{1}$ (XA-amine)*. Although no exciplex emissions can be seen in $\mathrm{CH}_{3} \mathrm{CN} / \mathrm{TEA}$, an exciplex emission with $\lambda_{\max } \approx 550 \mathrm{~nm}$ can be seen for DBA in cyclohexane $(\mathrm{CH}) /$ TEA $(2 \mathrm{M})$ and picosecond laser photolysis of DBA in CH/TEA $(1 \mathrm{M})$ gives rise to the appearance of not only an absorption band due to ${ }^{1} \mathrm{DBA}\left(S_{1}\right)$, i.e., a singlet-singlet $\left(S^{\prime} \leftarrow S_{1}\right)$ absorption band with $\lambda_{\max } \approx 620 \mathrm{~nm}$, but also an exciplex absorption band due to ${ }^{1}$ (DBA-TEA)* with $\lambda_{\max } \approx 680 \mathrm{~nm}$ (Nakayama et al 1993). Since the $S^{\prime} \leftarrow S_{1}$ absorption decays following a bi-exponential function with lifetimes of $\alpha_{1}=75 \mathrm{ps}$ and $\alpha_{2}=260 \mathrm{ps}$, and since the exciplex absorption increases at first with 
a rise time of $\alpha_{1}=75 \mathrm{ps}$ and then decreases with a lifetime of $\alpha_{2}=260 \mathrm{ps, \text {onecan }}$ conclude that ${ }^{1}(\mathrm{DBA}-\mathrm{TEA})^{*}$ is really produced in CH/TEA $(1 \mathrm{M})$. On the other hand, no exciplex absorption can be seen for DBA in $\mathrm{CH}_{3} \mathrm{CN} / \mathrm{TEA}(1 \mathrm{M})$ and the $S^{\prime} \leftarrow S_{1}$ absorption decays following a single exponential function with a lifetime of $50 \mathrm{ps}$ which is equal to the fluorescence quenching time by $1 \mathrm{M}$ TEA. For DBA in $\mathrm{CH} / \mathrm{TEA}(1 \mathrm{M})$, moreover, nanosecond laser photolysis reveals no formation of $\mathrm{DBA}^{-}$- and steady-state photolysis reveals that the rate of debromination is extremely slow compared with that in $\mathrm{CH}_{3} \mathrm{CN} / \mathrm{TEA}$. Hence, we have concluded that the spectra with bands $D-F$ shown in figure 5 are really a result of the absorptions of $\mathrm{XA}^{-}$- and that ${ }^{1}(\mathrm{DBA}-\mathrm{TEA})^{*}$ produced in $\mathrm{CH} / \mathrm{TEA}$ decomposes very slightly into $\mathrm{DBA}^{-}{ }^{-}$and $\mathrm{TEA}^{+}$, i.e., the formation of haloanthracene radical anions is essential for the photochemical dehalogenation of haloanthracenes by amine.

\section{References}

Bunce N J, Kumar Y, Ravanal L and Safe S 1978 J. Chem. Soc., Perkin Trans. 2880

Bunce N J, Pilon P, Ruzo L O and Sturch D J 1976 J. Org. Chem. 413023

Chittin B, Safe S, Bunce N, Ruzo L, Olie K and Hutzinger O 1978 Can. J. Chem. 561253

Davidson R S and Goodwin J W 1981 Tetrahedron Lett. 22163

Fulara J and Latowski T 1990 Pol. J. Chem. 64369

Hamanoue K, Hidaka T, Nakayama T, Teranishi H, Sumitani M and Yoshihara K 1983 Bull. Chem. Soc. Jpn. 561851

Hamanoue K, Kimoto M, Nakayama T, Teranishi H, Tagawa S and Tabata Y 1984a Radiat. Phys. Chem. 24445

Hamanoue K, Nakayama T, Ikenaga K and Ibuki K 1992 J. Phys. Chem. 9610297

Hamanoue K, Nakayama T, Ikenaga K, Ibuki K and Otani A 1993 J. Photochem. Photobiol. A69 305

Hamanoue K, Tai S, Hidaka T, Nakayama T, Kimoto M and Teranishi H 1984b J. Phys. Chem. 884380

Hamil W H 1986 Radical ions (eds) E T Kaiser and L Kevan (New York: Wiley) chap. 9

Iwamura H and Eaton D F 1991 Pure Appl. Chem. 631003

Nagamura T, Nakayama T and Hamanoue K 1991 Chem. Lett. 2051

Nagamura T, Nakayama T and Hamanoue K 1992 Chem. Phys. Lett. 19330

Nakayama T, Hanada T, Ibuki K and Hamanoue K 1993 Chem. Phys. Lett. 209367

Ohashi M, Tsujimoto K and Seki K 1973 J. Chem. Soc., Chem. Commun. 384

Saeva F D 1990 Top. Curr. Chem. 15661

Shida T 1988 Electronic absorption spectra of radical ions (Amsterdam: Elsevier)

Soloveichik O M, Ivanov V L and Kuz'min M G 1989 High Energy Chem. (Engl. Transl.) 23281

Tanaka M, Tanaka I, Tai S, Hamanoue K, Sumitani M and Yoshihara K 1983 J. Phys. Chem. 87813

Tsujimoto K, Tasaka S and Ohashi M 1975 J. Chem. Soc., Chem. Commun. 758 